\title{
Measuring the vulnerability of sub-national regions: Integrating relative location
}

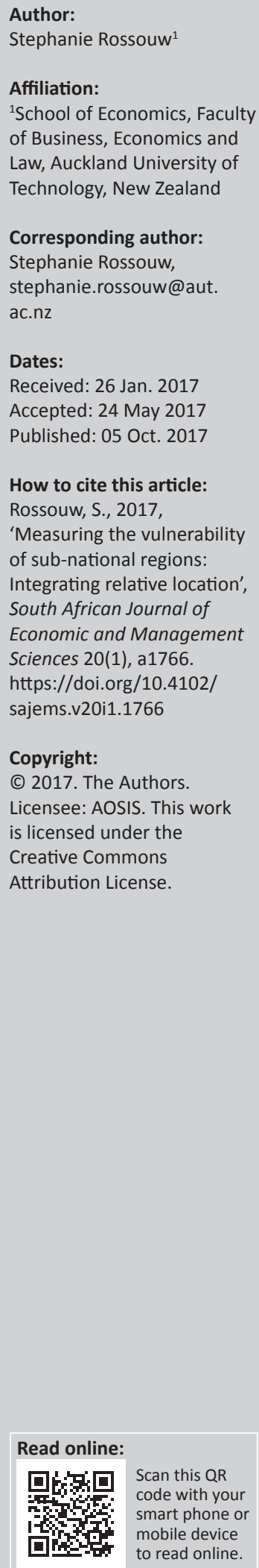

Background: The authors of this article 'Measuring the vulnerability of sub-national regions in South Africa' (Naudé, McGillivray and Rossouw 2009b) present an exploration into economic vulnerability from a sub-national perspective. It is an important contribution because it recognises the heterogeneous nature of vulnerability across areas within a country, but its analysis is aspatial because it does not explicitly account for the relative location of or the potential for spillovers between areas.

Aim: This article aims to provide a purely methodological contribution towards the debate surrounding the measurement of multidimensional vulnerability by: (1) augmenting Naudé et al. (2009b)'s model to take account of spatial contiguity, (2) comparing spatial and aspatial local vulnerability indices estimates to illustrate the presence and importance of spatial spillovers between contiguous areas and (3) extending their methodology on the Vulnerability Intervention Index to present results which highlight areas that are performing better and worse than expected.

Methods: Principal components analysis, queen-contiguity weight matrix and local indication of spatial association (LISA) maps were utilised.

Results: Application of the methodological extensions to South African Magisterial District data illustrates the presence and importance of spatial spillovers in shaping local vulnerability.

Conclusions: Our results illustrate a clear urban-rural vulnerability divide and the need for appropriate policy. It is argued that account of spatial spillovers is an important issue if full and accurate vulnerability indices are to be identified.

\section{Introduction}

Economic vulnerability is a multidimensional, multi-faceted concept. Its (re-)definition and (re-)measurement are not new areas of academic interest, but recently there has been a shift in thinking about economic vulnerability associated with the belief that the alleviation of poverty is a prerequisite for the achievement of development goals. Naudé, McGillivray and Rossouw (2009b) highlighted that most previous measures of vulnerability are potentially biased because they exclude environmental and/or geographical factors. Moreover, they recognised that the growing vulnerability literature has a focus at either the national or household level, which led them to emphasise the need for a characterisation and measurement of vulnerability at the sub-national area level. They attempted to fill these gaps in the literature by:

- advocating a method of sub-national vulnerability measurement through the construction of a Local Vulnerability Index (LVI) that includes environmental and geographical factors as integral components and

- conditioning their LVI on income per capita to yield a Vulnerability Intervention Index (VII).

Though the augmentation of models to include standardised variables pertaining to environmental and geographical factors is significant, a crucial aspect that was not integrated into their analysis is the potential influence on vulnerability of spillovers between areas. Anything that is observed to have a spatial dimension also has the potential to encounter spatial spillovers. Tobler's (1970) first law of geography is that 'everything is related to everything else, but near things are more related than distant things', and most geographers are aware that many if not most socio-economic variables have a spatial component.

Note: This article is based on the working paper titled 'Sub-national vulnerability and relative location: A case study of South Africa'. This working paper was published in the Auckland University of Technology working paper series, available at: http://www.aut.ac.nz/_data/ assets/pdf_file/0007/257497/Economics-WP-2012-01.pdf 
Spatial spillovers are features whereby the attributes of an area are influenced by the attributes in nearby or contiguous areas. The relative location of an area may be important when considering vulnerability because the population and policymakers of that area may compare it to other areas that they are most familiar with, and these areas are often ones that are contiguous or close by. An individual's perception of being in poverty, and the importance and selection of alleviating policy, may be a relative concept.

This article provides a purely methodological contribution to the existing literature regarding measurement and analysis of regional multidimensional vulnerability through augmenting the methodology of Naudé et al. (2009b). This will be achieved through: (1) expanding their principal components model to take account of spatial contiguity, that is, the physical contact of an area's geographical boundary by another area, (2) comparing spatial and aspatial Local Vulnerability Indices to illustrate the importance of spatial spillovers between areas, and (3) extending their VII method and subsequently presenting results which highlight areas that are performing better and worse than expected. Application of these augmented economic vulnerability indices to the same data used by Naudé et al. (2009b) (South African Magisterial District level data) provides us with a critically important platform by which we can compare our results to those generated by Naude et al. (2009b) and draw conclusions which suggest that the inclusion of a spatial dimension is crucial in ascertaining location-specific economic vulnerability. Not appreciating the impacts of spatial spillovers will potentially bias results and lead to incorrect policy recommendations. The contribution of this article is thus vitally important for future empirical studies investigating regional vulnerability as the spatial dimension can no longer be disregarded.

This article is structured as follows: the next section reviews the literature on vulnerability and critically reviews the content and approach of Naudé et al. (2009b). The 'Towards a spatial perspective' section argues that a sub-national perspective on vulnerability should take explicit account of relative location. The 'Data' section describes the data. The 'Methodological extensions and applications' section details augmentations and new results of Naude et al. (2009b)'s model that incorporate spatial and aspatial Local Vulnerability and Vulnerability Intervention Indices. The 'Caveats, conclusions and avenues for future research' section addresses the caveats of this study and provides conclusions as well as avenues for future research.

\section{Literature review}

\section{Vulnerability origins and the spatial scale of analysis}

The origins of vulnerability transcend the geographical, economic and political. Primary concerns associated with negative events are their impacts on productivity growth, development potential and the extent to which they alter vulnerability (Guillaumont 2004). ${ }^{1}$ However, before vulnerability can be accurately measured, attention needs to be focused on where potential shocks may arise. Three basic channels of origin can be identified: (1) environmental or natural shocks, such as natural disasters; (2) other external shocks (trade and exchange related), such as slumps in external demand, and (3) other (non-environmental) internal shocks, such as political instability (Guillaumont 2004).

Once the origins of vulnerability have been identified, the next stage in any vulnerability empirical analysis is to decide on the appropriate spatial scale. Literature pertaining to the study of vulnerability has focused on three levels of analysis: household, regional and national. A large majority of this literature is devoted to measuring the relative vulnerability of a country. ${ }^{2}$ Turvey (2007) advocates the need for placespecific vulnerability indices and constructed a Composite Vulnerability Index for 100 developing countries out of four sub-indices: a coastal index, a peripherality index, an urbanisation index and a vulnerability to natural disasters index. She argued that if the measurement of vulnerability excludes a geographical component, then the construction of vulnerability profiles might be useless for framing development policy and evaluating developing countries. ${ }^{3}$

Although the majority of analysis has focused on the countrylevel spatial scale, there are a growing number of articles that examine vulnerability at the household level. For instance, Bird and Prowse (2008) investigated the vulnerability of households in Zimbabwe and found that if official donors did not intervene then the poor and very poor were likely to be driven into long-term chronic poverty and such chronic poverty would be extremely difficult if not impossible to reverse. Gaiha and Imai (2008) also argued that idiosyncratic shocks (e.g. unemployment or illness) were the primary cause of Indian rural households' vulnerability, although poverty and aggregate risks (weather and crops) were also important contributory factors; the last of these is clearly a geographical issue. ${ }^{4}$

Not a lot of attention has been given to the vulnerability of regions within a country. Hulme, Moore and Shepherd (2001) linked poverty to the vulnerability of specific regions, and Kanbur and Venables (2005) showed that not only is spatial inequality between regions on the increase but it will

1. For a more in-depth discussion on the empirical and conceptual viewpoints of (12003) and Atkins, Mazzi and Easter (2000). Guilloumont (2009) su upsurge in interest concerning macro vulnerability because of the unsustainability of growth episodes and contemporaneous increase in poverty rates in Africa, the Asian crisis' unveiling of emerging markets' vulnerability and the debate surrounding the construction of an appropriate vulnerability measure that can be applied for specific country groups.

2.Baliamoune-Lutz and McGillivray (2008) identify that the World Bank's Country Policy and Institutional Assessment (CPIA), under which a country is classified as being more or less vulnerable, has some severe flaws that can result in the incorrect classification of countries located close to classification boundaries. Unfortunately, this has significant policy implications as CPIA ratings are used in deciding how International Development Association (IDA) assistance is allocated.

3.For further studies on country-specific vulnerability, see Birkmann (2007), Easter (1998), Marchante and Ortega (2006), Mansuri and Healy (2001) and McGillivray, Naudé and Santos-Paulino (2008).

4.Other household level vulnerability studies include Glewwe and Hall (1998), Chaudhuri, Jyotsna and Suryahadi (2002) and Kühl (2003). 
ultimately cause an overall increase in the inequality of specific countries. Similarly, Ivaschenko and Mete (2008) presented evidence of poverty traps and argued that higher levels of poverty in a region appear to reduce radically the chance of a household emerging out of poverty and that living in a region with a slow economic growth weakens the odds of a household exiting poverty and increases its risk of slipping into poverty. ${ }^{5}$

As regards to South Africa, vulnerability as currently understood in this and the Naudé et al. (2009b) paper has not been high on the priority list. There are studies which comes close in nature to this article but focuses either on quality of life (see Greyling \& Rossouw 2016; Naudé, Krugell \& Rossouw 2009a; Rossouw \& Naudé 2008) or ex post poverty outcomes (see Alderman et al. 2000; Klasen 2000; Mattes, Bratton \& Davids 2003; Noble et al. 2006). This reiterates the importance of increasing the literature base available as regards to incorporating spatial contiguity as regards to vulnerability measures.

\section{Naudé, McGillivray and Rossouw (2009b)'s contribution}

Much development literature still relies on income per capita measures as an indication of development and vulnerability. Naude et al. (2009b) underscore the shortcomings of focusing only on incomes when assessing vulnerability by stating that 'equal incomes do not translate into equal outcomes for all ... (and) different people are faced with different environments for translating income gains into non-income wellbeing gains' (p. 4). An important, though not new, contribution of their study was to emphasise that vulnerability is a multidimensional phenomenon that requires and deserves a multidimensional analysis. It is uplifting to see this underlying multidimensional theoretical perspective being adopted empirically in their subsequent analysis. They constructed a composite index of local vulnerability using principal component analysis (PCA). ${ }^{6}$ The execution of $\mathrm{PCA}^{7}$ is thought to reveal the internal structure of the data with each component being ranked in accordance with its importance to the multidimensional phenomena and with the first component known to capture most of the data's variability.

In line with theoretically driven multidimensional considerations, Naudé et al. (2009b) proposed the construction

\footnotetext{
5.The direction of causation should remain a moot point, although it is not explicitly addressed here Greater income per capita should permit development that reduces vulnerability, but lower vulnerability should permit more efficient reduces vulnerability, but lower vulnerability should permit more
allocations of resources that should stimulate greater income per capita.

6.Advantages of the PCA technique include that: (1) it does not require the assumptions of correlation between variables that are due to a set of underlying latent factors (as would need to be the case when applying factor analysis); and (2) the application of PCA should permit in-depth comparison of results with Naudé et al. (2009b) and permit methodological development.

7.Other approaches followed include: Glaeser et al. (2000) which standardised responses to various survey questions and then simply adding them together in order to derive an index of trust; and Mauro (1995) uses the average of indices such as political and labour stability, corruption and terrorism - and then uses this average as a regressor in models of growth and investment across countries and to determine institutional efficiency and corruption. He deems his strategy as correct because many of these indices measure the same fundamental trend. Lubotsky and Wittenberg (2006) proposed that a regression with multiple proxies might provide better results than that of principal components.
}

of an LVI based on 10 different and distinct domains, ${ }^{8}$ which are constructed from sub-domains stated in brackets:

- Size of local economy [gross domestic product (GDP), population size, population density, urbanisation rate]: It is argued by Liou and Ding (2004) that larger economies are prone to being less vulnerable.

- International trade capacity (ratio of exports and imports to local GDP, export diversification): As was stated by Briguglio (1995) and Matthee and Naudé (2007), the wider the range of goods being exported and the more open a region is to trade, the less vulnerable the region will be.

- Development (human development index [HDI], percentage age of local population in poverty, unemployment rate): The relationship between a region's vulnerability and its level of development is inverse, and therefore, it can be argued that the higher the level of development, the lower the vulnerability of said region.

- Demography and health (incidence of HIV and/or AIDS, population growth rate): The region's resilience in terms of negating internal or external shocks may be dependent of the stress placed on its health services because of a higher HIV incidence or above average population growth rate.

- Environment (percentage degraded land, proportion of forest-covered land and waterbodies, wetlands and rainfall): The quality of the environment influences household incomes and their perceived quality of life.

- Financial system (number of people per bank branch, ratio of the percentage age share of the country's financial sector in a particular area): This domain is essential when dealing with financial shocks. The less access people have to formal financial services, the more vulnerable they are seen to be.

- Structure of the local economy (share of primary production in total production): The less diversified a specific region is in regard to their production of goods and services, the more vulnerable they are likely to be.

- Peripherality (distance from the market): It was argued by Turvey (2007) and Briguglio (1995) that the longer the distance to the nearest market hub of activity, the more vulnerable a place will be.

- Income volatility (standard deviation of GDP growth): According to Liou and Ding (2004), a region's income volatility reflects an area's income 'riskiness'.

- Governance (per capita capital budget expenditure): In this domain, the article attempts to capture the ability of local governments to endorse pro-poor policies. Although this is not the perfect proxy to measure 'good governance', it can be argued that regions experiencing low per capita capital budget expenditures could also face higher future vulnerability as they lack the necessary resources for long-term development.

It should be emphasised that Naudé et al. (2009b) include both geographical and environmental indicators, which they

8.The choice of using ten domains and its associated variables comes from indices compiled by the CPIA, CIFP (2006), USAID (2006), Anderson (2007), Liou and Ding (2004), Briguglio (1997) and Turvey (2007). However, the range of variables used differs across these studies and number from 70 to 3 . 
strongly and correctly suggest are important for economic vulnerability measurement. They applied the following structured method to a data set detailed in the 'Data' section. Initially, PCAs were run on each of the individual domains that had more than one sub-domain (i.e. domains 1-6). Although it would be possible to appoint different weights to each subsequent component, this would require an appropriate selection of weights. Instead, the principal components of each of the individual domains PCA's results were selected and pooled into a data set that already contained the non-multidimensional individual domains (i.e. domains 7-10). Then, a second PCA was estimated on these data and the principal component again chosen for subsequent interpretation; the result is a single principal component used to represent their multidimensional LVI from which district ranks and area comparisons can be made. Note that each of Naudé et al. (2009b)'s domains are aspatial by construction: each area's estimate does not explicitly consider what is happening in an area's neighbouring areas.

Naudé et al. (2009b) also propose the construction of a VII that is designed to reflect the vulnerability associated with per capita income, such that:

$L V I_{i}=\alpha+\beta Y_{i}+\mu_{i}$

[Eqn 1]

where

$i=1, \ldots, 354$

where $\alpha$ is an intercept, $\beta$ is a slope coefficient, $Y$ is the per capita income of magisterial district $i$ and $\mu$ is the wellbehaved error term. If $\beta$ is equal to one, then any change in the LVI is a proportional response to the corresponding change in income per capita. Assuming that there are no scale returns disparity issues across areas, estimation of equation: (1) leads to a vector of residuals, one for each area, where each individual residual represents the deviation between the actual and the predicted LVI based on per capita income. Naudé et al. (2009b) examined the absolute values of these residuals to identify areas which deviate strongly from the average and found that although the LVI was highly correlated with per capita income (with greater income per capita being associated with lower vulnerability) it was far from being equal to unity; this led them to believe that there were reasons other than achieved incomes that drive vulnerability levels. ${ }^{9}$ As far as policy formation is concerned, this belief is in line with the suggestion that any policies aimed at reducing area level vulnerability should not rely solely on increasing incomes.

\section{Towards a spatial perspective}

As each of Naudé et al. (2009b)'s domains are aspatial by construction, their LVI and VII measures are also aspatial: using the above methods implicitly assumes that relative

9.The direction of causation should remain a moot point although it is not explicitly addressed here. Greater income per capita should permit development that
reduces vulnerability, but lower vulnerability should permit more efficient allocations of resources that should stimulate greater income per capita. location is not important. However, the literature emphasises that of crucial importance for vulnerability assessments is the relative location of an area. For instance, Chauvet and Collier (2005) stressed the importance of spatial spillover effects from fragile neighbouring countries and calculated that the negative effects of having fragile neighbours average $1.6 \%$ of GDP per annum. Tondl and Vuksic (2003) emphasised the importance of contiguity and spatial dependence at the regional scale by showing that a region's growth is significantly more likely to be higher if it is a neighbour of another high growth region. They estimated that about a fifth of a region's growth is determined by that of surrounding regions. Similarly, Florax and van der Vlist (2003) suggested that it is necessary to include 'neighbourhood' effects in explaining the spatial distribution of indicators related to wages, crime, health and schooling.

Empirical investigations into vulnerability issues will be inefficient if account has not been taken of spatial spillovers. Spatial autocorrelation, that is, the degree of dependency among observations in a geographic space, will be an important consideration in any modelling procedure if there are processes operating across space, as exemplified when adjacent observations are not independent of each other. Naudé et al. (2009b) are not alone in the lack of recognition of the importance of relative location and spatial autocorrelation. For instance, although Bird, McKay and Shinyelawa (2007) emphasise that a location's attributes have a significant influence on poverty traps, it is not simply the attributes of the location in isolation that are important but also the attributes of an area's relative location. A better understanding of how area specific attributes contribute to the creation and sustainability of place-specific vulnerability is prudent, but it may be superior to improve contemporaneously our understanding of how one area contributes to another area's vulnerability.

One of the clearest expositions of the reasons why spatial autocorrelation in socio-economic variables can occur has been provided by Voss et al. (2006) who emphasised the importance of, among other things, feedback, grouping forces and grouping responses. These can be positive or negative and could result in some areas being vulnerability black-spots.

There is the potential for feedback forces to influence individuals and households' preferences and activities, willingness to accept greater vulnerability and activities to reduce vulnerability. Ceteris paribus, the smaller the spatial scale of analysis, the higher the likelihood and frequency of contact between individuals and the greater the potential feedback between individuals and between policy-makers, and often between individuals and policy-makers. Greater similarity in socio-economic measures and conditions will mean less justification for individuals to perceive that they are relatively more vulnerable. For reasons related to the adoption/diffusion theory (Rodgers 1962) and the agent interaction theory (Irwin \& Bockstael 2004), we should expect there to be the potential for spatial spillovers in underlying vulnerability dimensions with a positive correlation in 
dimensions between contiguous areas. For instance, unemployment rates tend to have some degree of imitation across areas correlated with, for example, similarities in the cultural acceptance of being unemployed. Individuals might incorrectly associate unemployment benefits or social grants received for children with more leisure time or freedom from not working and therefore follow suit. This could ultimately increase the vulnerability of the area or group of areas.

Geographically proximate districts with similar socioeconomic attributes and vulnerability dimensions are more conducive to grouping forces, such as the formulation of parallel policy initiatives. The clustering of underlying vulnerability dimensions across space might be because of a number of reasons including policy that has been applied to groups of areas or socio-economic issues that lead to spatial clustering (e.g. high house prices force low-income people into other areas and seaports attract international trading activities). In South Africa, as in various developing countries, there is a serious problem with informal (slum) settlements. Informal settlements are the illegal and unauthorised occupation of private or government owned land and consist of dwellings usually made out of corrugated metal. Typically, these informal settlements found on the periphery of large urban areas are established by unemployed, impoverished, illiterate, homeless or illegal migrants who may respond in similar ways to policies because of their socio-economic circumstances.

Alternatively, grouping responses can occur where the application of policy is reacted to in similar ways, often because of the spatial clustering of similar socio-economically characterised individuals. As the people occupying informal settlements share the same plight, they tend to assemble and demand ownership of the occupied land as well as the installation of water and refuge systems. If they do not receive what they demand, then protests can be organised which may cause damage not only to the reputation of the area but also to public property such as schools, libraries and so on. Such demonstrations could greatly increase the vulnerability of a specific area and its neighbours.

Sub-indices used for the construction of vulnerability indices are particularly likely to possess a spatial dimension. For instance, the size of the local economy domain is based on GDP, population size, population density and urbanisation rate, factors which are likely to have high (low) values in areas that are contiguous to areas also with high (low) values. As a result, two important considerations arise: firstly, if the spatial evolution of socio-economic attributes is by accident, fate or otherwise, then recognition of such spatial patterns when formulating policy could improve the effectiveness of the policy; secondly, application of policy designed to alleviate vulnerability should not be focused on one area without contemporaneously and explicitly considering similarities across neighbouring areas. This perspective is supported by Chauvet, Collier and Hoeffler (2007) who argue that because failing regions impose a large cost on their neighbours it is not only required but also justified to have cross-region intervention in decision-making processes.
Policy directed towards reducing vulnerability needs to have a spatial dimension and can be articulated into two simple groups. Firstly, areas may suffer higher levels of vulnerability because they are distinctly different from other areas, including those areas which are contiguous. In this case the policy would need to be area specific and designed to improve the vulnerability of the area in isolation. Secondly, areas may suffer higher levels of vulnerability because they are influenced by spatial spillovers. In this case, the appropriate policy would need to be targeted towards not simply the specific area but also the group of contiguous areas. ${ }^{10}$

In summary, a lack of appreciation of the spatial autocorrelation that is present in sub-domains may result in the under-specification of a model and inefficient vulnerability estimates. Modelling under-specifications and inefficient vulnerability estimates can result in sub-optimal and inappropriate policy formation.

\section{Data}

Naudé et al. (2009b) applied their methodology to South African data. To illustrate the strengths and important methodological contribution of this article, we apply our extension of Naudé et al. (2009b)'s methodology to the same data set, which was acquired for all of South Africa's magisterial districts over the period 1996 to 2006.

South Africa is classified as an upper-middle-income country, with a Net National Income ${ }^{11}$ per capita of approximately US\$ 10 892, an overall GDP of US\$ 692 billion and an estimated population of 54 million. She experienced exceptionally high inflows of foreign capital and foreign direct investment since 2003 which assisted in speeding up the process of employment creation; for instance, during the year ending 2014/2015, just over a million jobs were created. In saying this, unemployment remains severe in spite of a considerable drive for further job creation and poverty reduction. Although South Africa is not classified as a vulnerable state in the traditional sense, the international community recognises the role its strong institutions have played in bringing about these improvements. In the absence of these institutions, South Africa could be rendered vulnerableas it is plagued by unrelenting high unemployment, widening inequality, poverty, AIDS-related deaths and a rapid increase in the crime rate. Demombynes and Özler (2005) argued that a direct link exists between this crime rate and the degree of local inequality thereby reinforcing the

10.Friedmann (1963) argues that a country could be divided into the following development areas: (1) metropolitan development, (2) transitional-upward, (3) frontier regions and (4) transitional-downward areas. Although each area has its own local development opportunities, they do form a spatial system, and a country's rate of growth would be constrained if it ignores the problems of the less developed and more vulnerable transitional-downward areas. Thus, any policy decisions should explicitly consider surrounding areas. Ward and Bn policy decisions should explicitly consider surrounding areas. Ward and Brown (2009) argue that regional policy should be directed towards low developing regions but be changed according to the area-specific problems.
bo

11.Net national income (NNI) is gross domestic product plus net receipts of wages, salaries and property income from abroad, minus the depreciation of fixed capital salaries and property income from abroad, minus the depreciation of fixed capital
assets (dwellings, buildings, machinery, transport equipment and physical infrastructure) through wear and tear and obsolescence (OECD 2015). 
TABLE 1: Data description.

\begin{tabular}{|c|c|c|c|c|c|}
\hline Variable & Source & Mean & Standard deviation & Maximum & Minimum \\
\hline GDP per magisterial district & IHS ReX data & 30121387 & 95229631 & 119612638 & 24409 \\
\hline Total population & IHS ReX data & 127408 & 157519.5 & 1139848 & 3866 \\
\hline Population density & IHS ReX data & 255.51 & 935.82 & 9707.23 & 0.351 \\
\hline Urbanisation rate (\%) & IHS ReX data & 0.52 & 0.335 & 1 & 0 \\
\hline Proportion of primary production & IHS ReX data & 0.22 & 0.185 & 0.91 & 0.0006 \\
\hline Exports as (\%) of GDP & IHS ReX data & 0.06 & 0.189 & 2.76 & 0 \\
\hline Diversity in exports & Matthee and Naudé (2007) & 0.67 & 0.284 & 1.89 & 0.14 \\
\hline Distance from closest hub/market & Matthee and Naudé (2007) & 226.11 & 131.46 & 684.76 & 0 \\
\hline HDI & IHS ReX data & 0.52 & 0.094 & 0.83 & 0.28 \\
\hline Number of people in poverty as $\%$ of total population & IHS ReX data & 0.51 & 0.206 & 0.97 & 0.062 \\
\hline Unemployment rate $(\%)$ & IHS ReX data & 0.4 & 0.191 & 0.9 & 0.03 \\
\hline Volatility in income & IHS ReX data & 0.03 & 0.009 & 0.07 & 0.012 \\
\hline Total people HIV+ & Quantec Easydata & 11285 & 15002.7 & 126479 & 1 \\
\hline Per capita capital budget expenditure $\left(R^{\prime} 000\right)$ & Statistics South Africa & 388.28 & 1217.06 & 26761.86 & 2.68 \\
\hline Degraded land $(\%)$ of total area & IHS ReX data & 0.07 & 0.12 & 0.68 & 0.000003 \\
\hline Total land cover $\mathrm{km}^{2}$ (forest, waterbodies and wetlands) & IHS ReX data & 39.95 & 86.69 & 742.77 & 0.015 \\
\hline Average rainfall (annual mm) & IHS ReX data & 639 & 316.90 & 2912.57 & 25.9 \\
\hline No. of population per bank branch & Naudé et al. (2008) & 83643 & 95164.64 & 690504 & 4369 \\
\hline $\begin{array}{l}\text { Relationship between (\%) of South Africa's financial services and } \\
(\%) \text { of SA's population }\end{array}$ & IHS ReX data & 0.10 & 0.07 & 0.4 & 0.004 \\
\hline
\end{tabular}

GDP, gross domestic product; HDI, human development index; IHS ReX, IHS's Regional Economic Explore.

general consensus of institutions responsibility for implementing policies to eradicate poverty and inequality. ${ }^{12}$

The National Development Plan (NDP) was formally launched in 2013 to help the South African Government eliminate poverty and reduce inequality by 2030 (NPC 2013). The NDP concluded that in order to achieve these social objectives South Africa would need to keep growing at a rate of $5.7 \%$ per annum until 2030, and there should be a concurrent reduction of deficiencies in state organisations, capacity and leadership. This target is said to be achievable by focusing on two key variables: the rate of economic growth and the employment intensity of that growth. ${ }^{13}$

To conduct the empirical analysis, data were compiled from various sources, as shown in Table 1 . The spatial scale of our analysis is the same as Naudé et al. (2009b) and is based on the analysis of 354 magisterial districts. It should however be pointed out that the demarcation of South Africa's municipality boundaries were changed by the Municipal Demarcation Board of South Africa (MDB 2016) three times since and including the years 2000, 2006 and 2011. This would naturally provide problems when analysing municipal data over time. Fortunately, a unique feature of the utilised IHS's Regional Economic Focus' (REF) (see http://www.ihsglobalinsight. co.za/) Regional eXplorer (ReX) database is the inclusion of these changes in the demarcation of municipalities and its ability to adjust the data accordingly. This study uses a data set that has been adjusted for the 2006 demarcation boundary

12.The spreading of HIV and AIDS is also a big concern for South Africa and McDonald and Roberts (2006) argued that the marginal impact on income per capita of a $1 \%$ increase in the prevalence rate is minus $0.59 \%$.

13.When comparing South Africa to other countries, it is interesting to note that she has a vulnerability index score placing her alongside France and Poland (Briguglio \& Galea 2003). However, Naudé et al. (2009b) argued that there is exceptional variation in the degree of vulnerability across her regions with large spatial variations in economic activities and institutional qualities contributing to uneven social and economic conditions. changes, thereby ensuring data for different years are directly comparable on a geographical basis.

Socio-economic variables have a spatial dimension. One way of examining spatial patterns is to exploit the spatial nature of a data set by constructing maps and estimating Moran's I statistics. Consider Figure 1 that shows a map of rates of poverty expressed as standard deviations away from the sample mean. ${ }^{14}$ It illustrates that poverty rates in South Africa have a spatial dimension. There is an East-West split with western (eastern) parts having relatively low (high) rates of poverty. Poverty rates are relatively low throughout the Western and Northern Capes and are relatively high in the North West and in the Free State. Generalisations are more difficult for Limpopo, KwaZulu-Natal, Mpumalanga and the Eastern Cape because of their relatively large variation in poverty rates. Urban areas appear to have relatively low rates of poverty, specifically Johannesburg, Durban, Cape Town, East London, Port Shepstone and Richard's Bay. Visual inspection suggests that areas with high (low) rates of poverty are more likely to be contiguous to areas that also have high (low) rates of poverty, at least at this spatial scale.

Moran's I values are produced to test statistically for spatial clustering, that is, similar values of a variable being present across areas that are located relatively close to each other. Typically, a Moran's I value is obtained via the Moran scatter plot, which in this case plots poverty rates on the horizontal axis and its (queen-contiguity) spatial lag on the vertical axis, as shown in Figure $2 .{ }^{15}$ The upper right quadrant of the Moran's I scatter plot shows those areas

14.To undertake these tasks, we employed the GeoDa open source software. This is free software and was developed at the Spatial Analysis Lab at the University of Illinois. It can be downloaded from: https://www.geoda.uiuc.edu/

15.That is any area that shares a common boundary with area $i$. Throughout this article, a queen-contiguity spatial-weights matrix is employed, and statistical significance of Moran's I statistics is based on the randomisation approach with 999 permutations. 


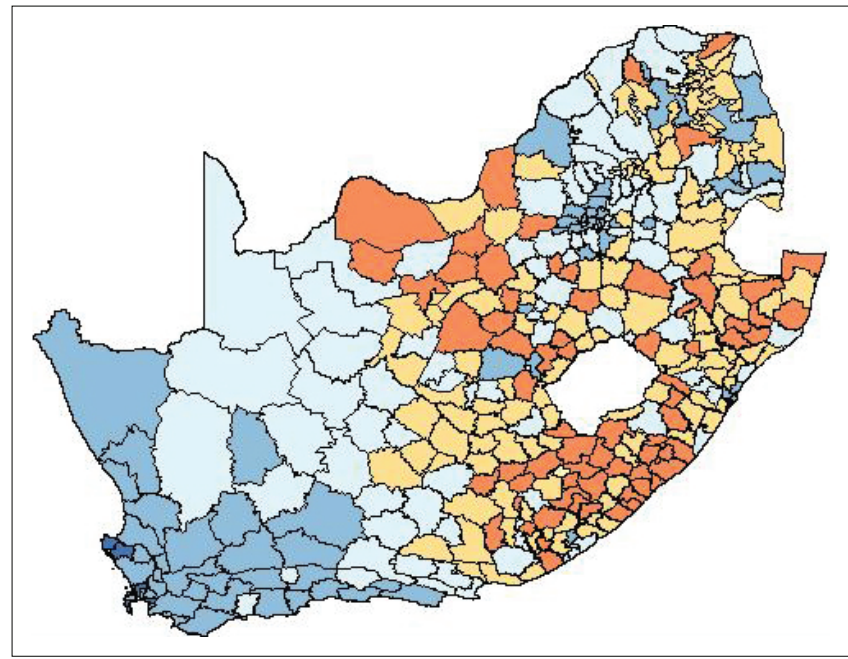

FIGURE 1: Poverty map.

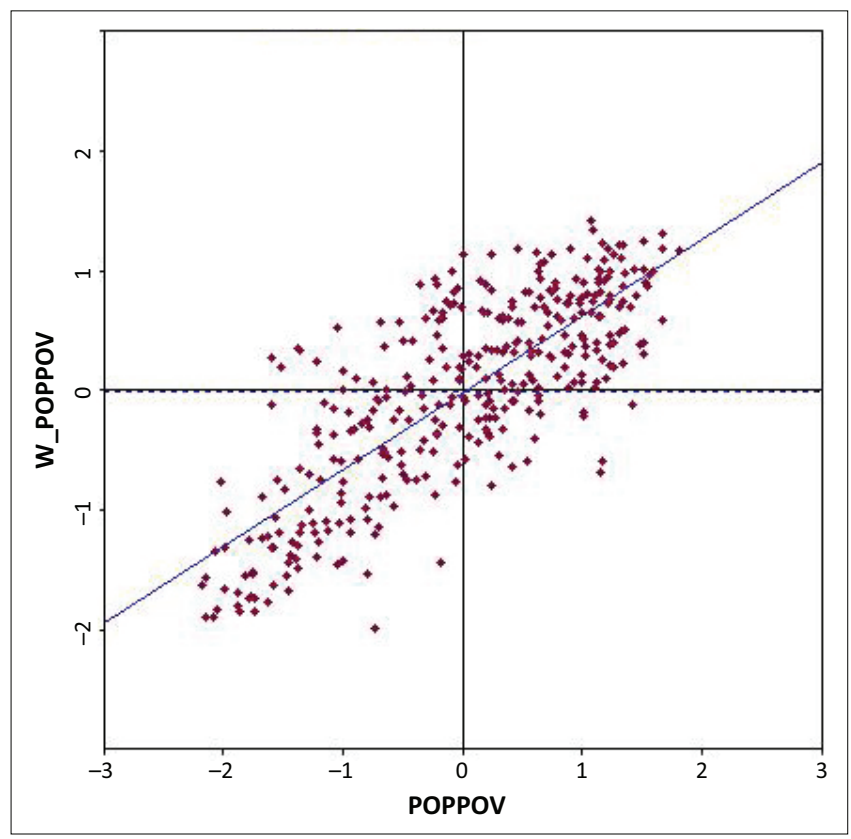

Note: Moran's $I=0.6410$.

FIGURE 2: Moran's I of poverty

with above average poverty values which share boundaries with neighbouring areas that also have above average poverty values (high-high). The bottom left quadrant highlights areas with below average poverty which have neighbouring areas that also have below average poverty values (low-low). The bottom right quadrant displays areas with above average poverty surrounded by areas that have below average poverty (high-low) and the upper left quadrant shows the opposite (low-high). The slope of the line through these points expresses the global Moran's I value (Anselin 1996). The Moran's I value of 0.641 , which is statistically significant at the $1 \%$ level, leads us to reject the null hypothesis that there is no spatial clustering. Hence, the visual interpretations of Figure 1 are supported with the quantitative results of Figure 2 and leads us to believe that spatial autocorrelation in socio-economic variables may be important in the construction of vulnerability indices.

\section{Methodological extensions and applications}

This section will illustrate the methodological contribution of this article to future empirical studies regarding the measurement and analysis of regional multidimensional vulnerability. Two major augmentations of Naudé et al. (2009b)'s methodology will be presented which are based on the following underlying concerns. Firstly, although their LVI includes both environmental and geographical indicators, it is aspatial in nature as each area's estimate does not explicitly consider what is happening in it neighbouring areas. Hence, they do not take into account explicitly the possible effects of spatial spillovers, and they treat all areas as though they were unconnected islands; this is extremely unlikely if there are important spillovers from one area on to its surroundings.

Secondly, they categorise districts into nine groups and subsequently convert them into a nine-point index, where members of group 1 have a value of 1 , group 2 have a value of 2 and so on. Categorisation into groups can be problematic and misleading if gaps between groups are arbitrary; for instance, an area with a very low value that is part of group 4 might actually be closer to a high value member in group 5 than a high value member in group 4 . This is similar to the criticism made by Baliamoune-Lutz and McGillivray (2008) on the World Bank's CPIA.

In other words, we extend the work of Naudé et al. (2009b) by addressing these two areas. Firstly, we construct a spatial LVI through the inclusion of queen-contiguity spatially weighted sub-domains, and secondly by retaining the final principal component value as determined by the LVI for each area in order to sustain a quantitative indicator of disparity between district $i$ and $j$ that is not affected by group categorisation.

\section{Augmentations of the Local Vulnerability Index and Vulnerability Intervention Index}

In contrast to Naudé et al. (2009b), we apply the following structured method:

- Begin with exactly the same original data and standardised variables as Naudé et al. (2009b). This is so as to ensure comparability of the various results obtained by the different studies.

- Replicate the estimates of Naudé et al. (2009b). This will generate a set of aspatial results that are not categorised using the nine-point index.

- Append original data to each area within a magisterial districts shapefile.

- Construct a spatial weight matrix that will permit the formation of new variables to capture spatial spillovers. This part of the process can use weights selected purely on theory, purely on statistical strength or on a combination of these two extremes. We commenced this process by weighting data for area $i$ by the corresponding values of the same variable in areas that are contiguous to area $i$ - these are called queen-contiguous weights. We 
constructed a series of other spatial weights, including rook, second-order queen and various distance weight matrices and then compared the results. We identified no qualitative differences across the final sets of empirical results and so decided to retain the queen-contiguity weight matrix throughout.

- Estimate PCAs for each of the individual domains listed 1-10 in Section 'Literature review'. Note that all individual domains will have double their original number of variables: the original standardised variables and their queen-contiguous spatially weighted equivalents.

- Retain and pool all individual domain PCA's principal components.

- Estimate a second PCA across these individual domain principal components and retain the principal component for interpretation. We retain the final principal component raw values for each managerial district in order to sustain a clear quantitative indicator of disparity between area $i$ and $j$. This is contrary to Naudé et al. (2009b) who instead categorised districts into nine groups.

The result is two principal components: one that will represent the multidimensional LVI from Naudé et al. (2009b)'s aspatial perspective and one that will represent the multidimensional LVI from a spatial perspective, which we denote by spatial Local Vulnerability Index (sLVI):

- Reconstruct Naudé et al. (2009b)'s VII to reflect vulnerability associated with per capita income. Estimating $L V I_{i}=\alpha+\beta Y+\mu_{i}(i=1, \ldots, 354)$ to replicate Naudé et al. (2009b)'s results and estimate $s L V I_{i}=\alpha+\beta Y_{i}+\mu_{i}$ to capture the spatial equivalent set.

- Save the vectors of residuals which represent the deviations between the actual and the predicted values for LVI and sLVI, respectively.

Interpret the absolute values of these sets of residuals and identify which areas deviate strongly from predicted.

It is emphasising that this retention and subsequent analysis of the residuals is a clear extension of the methodology employed by Naudé et al. (2009b), as they take the absolute residual values as an indication of the level of vulnerability of an area. Collating absolute values will muddle areas into a VII irrespective of whether they were performing much better (a good form of vulnerability) or much worse (a bad form of vulnerability) than expected under the fitted model. Good (and bad) forms of vulnerability may be the result of appropriate (and inappropriate) policy; for instance, some areas may have been influenced by beneficial policy or naturally occurring economic phenomena (such as urbanisation and localisation economies) that make areas perform better than would be expected otherwise, while the absence of appropriate policy (or the application of inappropriate policy) may result in the deterioration of other areas.

\section{Results of Local Vulnerability Index and spatial Local Vulnerability Index estimations}

Figures 3 and 4 present local indication of spatial association (LISA) maps based on the results of LVI and SLVI estimations.

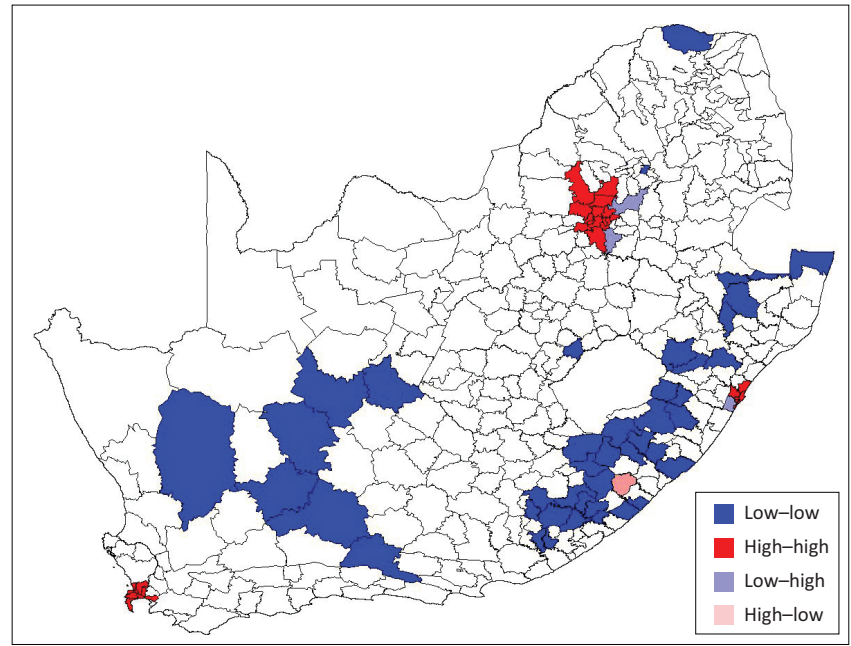

FIGURE 3: Local indication of spatial association map of Local Vulnerability Index estimates.

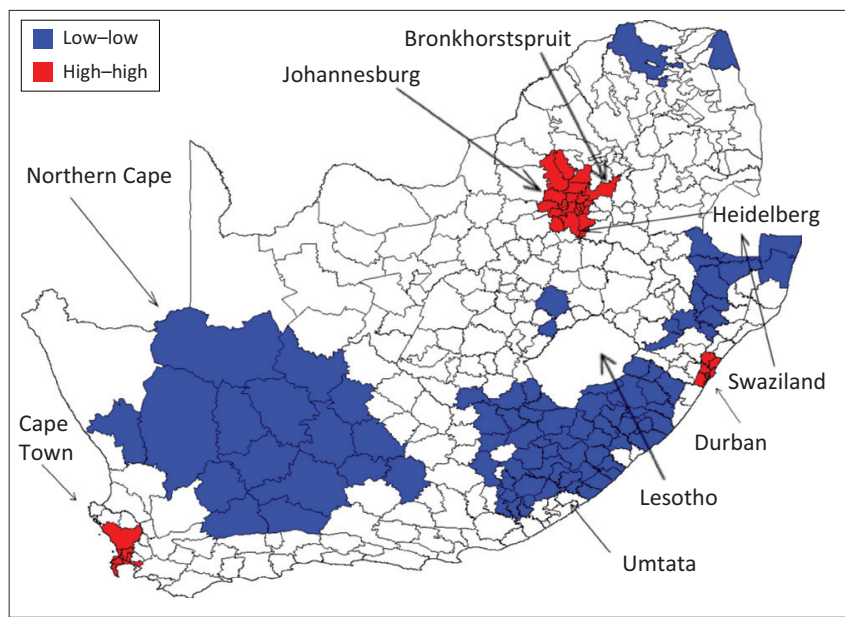

FIGURE 4: Local indication of spatial association map of Spatially Weighted Local Vulnerability Index estimates.

LISA maps are special choropleth maps that highlight those locations with a significant local Moran statistic classified by type of spatial correlation (Anselin 1995). They highlight areas with high (low) vulnerability that are surrounded by areas with relatively high (low) vulnerability; LISA maps can also highlight areas with high (low) vulnerability that are surrounded by areas with relatively low (high) vulnerability. Through visual inspection, it becomes clear that an appreciation of the influence of contiguity effects will affect LVI estimates.

Several observations obtainable from comparing Figures 3 and 4 are worth highlighting. Firstly, magisterial districts within and surrounding Cape Town, Durban and Johannesburg are least locally vulnerable. This emphasises a large urban-rural disparity vulnerability effect. The same pattern is not identifiable for other urban areas, with the only exception being Umtata. Taken together, the results suggest that Umtata is an area that is doing relatively well in comparison to its hinterland (see Figure 3), but it is at risk because its hinterland is performing relatively poorly and spatial spillovers might deteriorate the extent of vulnerability within this conurbation (see Figure 4). Umtata's extent of 
vulnerability could be the result of policies that have been directed at this large conurbation without concern for its surrounding hinterland.

Secondly, Figure 4 suggests that the greater hinterland of the three main urban areas of Cape Town, Durban and Johannesburg are much less vulnerable than those indicated in Figure 3. This is illustrated by the significant spillovers between contiguous districts which, in these cases, appear to diminish vulnerability. Such a contagion issue will be related to either spatial feedback, grouping or response forces. Of particular interest are the magisterial districts of Heidelberg and Bronkhorstspruit which are low-highs according to Figure 3 and high-highs according to Figure 4; these differences are because of the spatial spillovers between contiguous districts, and without these spatial spillovers, it is likely that these two districts would be much more vulnerable. An alternative perspective is that individuals are being marginalised in and around Johannesburg and are being forced out of relatively affluent areas and clustered into these two relatively poorly performing districts. Thus, policy geared towards diminishing the vulnerability of people in Heidelberg and Bronkhorstspruit should be both district specific (as highlighted in Figure 3) and take account of spatial spillovers (as highlighted in Figure 4). ${ }^{16}$

Thirdly, there are also important differences between Figures 3 and 4, which reflect differences in estimates obtained that result from the inclusion of spatially weighted sub-domains. The results presented in Figure 3 suggest that there are magisterial districts that suffer high levels of vulnerability, but the results presented in Figure 4 illustrate that this is not an attribute that stops at areas' borders. Instead, the most vulnerable areas are clustered and contiguous in several areas. Of most concern is: (1) magisterial districts occupying the area to the south of Swaziland and which continues, mainly inland, down to Ladysmith, (2) much of the eastern part of the Eastern Cape to the south of Lesotho, and (3) a large, central part of the Northern Cape. The extent of vulnerability is not fully emphasised in Figure 3; the reason why this spatial perspective is so important is because any attempts by policy-makers to alleviate vulnerability in these areas need to take a larger spatial perspective and explicitly consider large swathes of districts in their policy formations rather than simply considering the circumstances within specific districts in isolation.

When account of spatial spillovers in vulnerability subdomains is explicitly considered in the estimation process, the rankings of districts can differ substantially from estimates where account of spatial spillovers is excluded. Table 2 presents the sLVI estimates of the top and bottom 20 magisterial districts and each of these districts' ranks that have been replicated using the (non-spatial) LVI. Although there are some districts where the rank is unaffected, such as

\footnotetext{
16.Of particular note is that the results of Calvo (2008) suggest that the urban-rura vulnerability divide in Peru was not significantly increasing over time; our results, which use annual data between 1996 and 2006, indicate that this vulnerability which use annual data between 1996 and 2006, indicate that this vulnerability
divide is increasing in South Africa at a time when, and explicitly after 2000, policies are focused on achieving Millennium Development Goals.
}

TABLE 2: Local Vulnerability Index top and bottom 20 areas.

\begin{tabular}{|c|c|c|c|}
\hline Area & LVI & $\begin{array}{l}\text { Rank with spatial } \\
\text { weights }\end{array}$ & $\begin{array}{l}\text { Rank without } \\
\text { spatial weights }\end{array}$ \\
\hline Nelspruit & -1.736 & 1 & 1 \\
\hline Lower Umfolozi & -1.651 & 2 & 20 \\
\hline Thabazimbi & -1.613 & 3 & 2 \\
\hline Middelburg & -1.559 & 4 & 17 \\
\hline Phalabourwa & -1.425 & 5 & 3 \\
\hline Pietersburg & -1.391 & 6 & 6 \\
\hline Mmabatho & -1.378 & 7 & 26 \\
\hline Umtata & -1.337 & 8 & 63 \\
\hline Kimberley & -1.284 & 9 & 95 \\
\hline Worcester & -1.276 & 10 & 21 \\
\hline Postmasburg & -1.226 & 11 & 23 \\
\hline Highveld Ridge & -1.224 & 12 & 48 \\
\hline Witbank & -1.214 & 13 & 78 \\
\hline Rustenburg & -1.200 & 14 & 218 \\
\hline Soutpansberg & -1.194 & 15 & 7 \\
\hline Namaqualand & -1.183 & 16 & 16 \\
\hline Thohoyandou & -1.174 & 17 & 106 \\
\hline Bloemfontein & -1.158 & 18 & 228 \\
\hline Gordonia & -1.148 & 19 & 40 \\
\hline Letaba & -1.104 & 20 & 5 \\
\hline Bellville & 1.523 & 335 & 261 \\
\hline Cape & 1.613 & 336 & 339 \\
\hline Westonaria & 2.162 & 337 & 176 \\
\hline Umbumbulu & 2.218 & 338 & 235 \\
\hline Soshanguve & 2.270 & 339 & 348 \\
\hline Inanda & 2.431 & 340 & 347 \\
\hline Alberton & 2.570 & 341 & 343 \\
\hline Roodepoort & 2.659 & 342 & 292 \\
\hline Kempton Park & 2.684 & 343 & 337 \\
\hline Germiston & 2.790 & 344 & 230 \\
\hline Durban & 3.070 & 345 & 349 \\
\hline Randburg & 3.162 & 346 & 342 \\
\hline Wynberg & 3.224 & 347 & 344 \\
\hline Chatsworth & 3.775 & 348 & 341 \\
\hline Johannesburg & 3.883 & 349 & 353 \\
\hline Simonstown & 3.911 & 350 & 62 \\
\hline Goodwood & 3.943 & 351 & 346 \\
\hline Mitchells Plain & 3.979 & 352 & 352 \\
\hline Umlazi & 4.736 & 353 & 351 \\
\hline Soweto & 5.935 & 354 & 354 \\
\hline
\end{tabular}

LVI, Local Vulnerability Index.

Nelspruit (rank = 1) and Soweto (rank = 354), the estimates of the ranks of many other districts do alter substantially; for instance, Rustenburg's rank improves from 228th to 18th after taking into account spatial spillovers, while Simonstown's rank falls from 62nd to 350th. ${ }^{17}$

\section{Results of Vulnerability Intervention Index and Spatially Weighted Vulnerability Intervention Index estimations}

Residual estimates are presented for the top and bottom 20 districts in Table 3, and Figures 5 and 6 provide visual support. Table 3 highlights the importance of accounting for spatial spillovers in VII estimates; although the top three districts (Johannesburg, Soweto and Durban) only switch

17. One much highlighted issue concerning rankings is that they are highly sensitive to gaps in the underlying parameter. For instance, although the LVI estimate varies by a substantial margin of over 4 between the bottom 20 districts, the LVI value between the 20th and the 335th is only 2.5 . 
TABLE 3: Vulnerability Intervention Index top and bottom 20 areas.

\begin{tabular}{|c|c|c|c|}
\hline Area & VII & $\begin{array}{l}\text { Rank with spatial } \\
\text { weights }\end{array}$ & $\begin{array}{l}\text { Rank without } \\
\text { spatial weights }\end{array}$ \\
\hline Johannesburg & 6.473208 & 1 & 3 \\
\hline Soweto & 5.713385 & 2 & 1 \\
\hline Durban & 5.31242 & 3 & 2 \\
\hline Pretoria & 4.95736 & 4 & 13 \\
\hline Mitchells Plain & 4.489239 & 5 & 10 \\
\hline Umlazi & 4.087025 & 6 & 4 \\
\hline Port Elizabeth & 3.997531 & 7 & 18 \\
\hline Inanda & 2.757484 & 8 & 12 \\
\hline Pietermaritzburg & 2.725692 & 9 & 26 \\
\hline Soshanguve & 2.34368 & 10 & 21 \\
\hline Pinetown & 2.342031 & 11 & 14 \\
\hline Wynberg & 2.328639 & 12 & 8 \\
\hline Goodwood & 2.200749 & 13 & 6 \\
\hline Cape & 2.049173 & 14 & 16 \\
\hline Bloemfontein & 1.883006 & 15 & 34 \\
\hline Randburg & 1.8787 & 16 & 9 \\
\hline Lower Umfolozi & 1.75404 & 17 & 23 \\
\hline Rustenburg & 1.749878 & 18 & 50 \\
\hline Vanderbijlpark & 1.641831 & 19 & 37 \\
\hline Welkom & 1.622162 & 20 & 27 \\
\hline Moorreesburg & -1.00684 & 335 & 333 \\
\hline Vredendal & -1.00964 & 336 & 340 \\
\hline Victoria-West & -1.03966 & 337 & 308 \\
\hline Malmesbury & -1.04856 & 338 & 309 \\
\hline Namaqualand & -1.05074 & 339 & 349 \\
\hline Kriel & -1.06366 & 340 & 266 \\
\hline Piketberg & -1.07277 & 341 & 344 \\
\hline Clanwilliam & -1.07702 & 342 & 345 \\
\hline Uniondale & -1.08923 & 343 & 334 \\
\hline Belfast & -1.12213 & 344 & 338 \\
\hline Carolina & -1.12493 & 345 & 322 \\
\hline Bochum & -1.14423 & 346 & 342 \\
\hline Van Rhynsdorp & -1.15468 & 347 & 353 \\
\hline Bronkhorstspruit & -1.15722 & 348 & 157 \\
\hline Waterval Boven & -1.16347 & 349 & 352 \\
\hline Bredasdorp & -1.18536 & 350 & 351 \\
\hline Caledon & -1.24729 & 351 & 350 \\
\hline Ladysmith & -1.24927 & 352 & 347 \\
\hline Joubertina & -1.3033 & 353 & 348 \\
\hline Pelgrimsrus & -1.34627 & 354 & 346 \\
\hline
\end{tabular}

VII, Vulnerability Intervention Index.

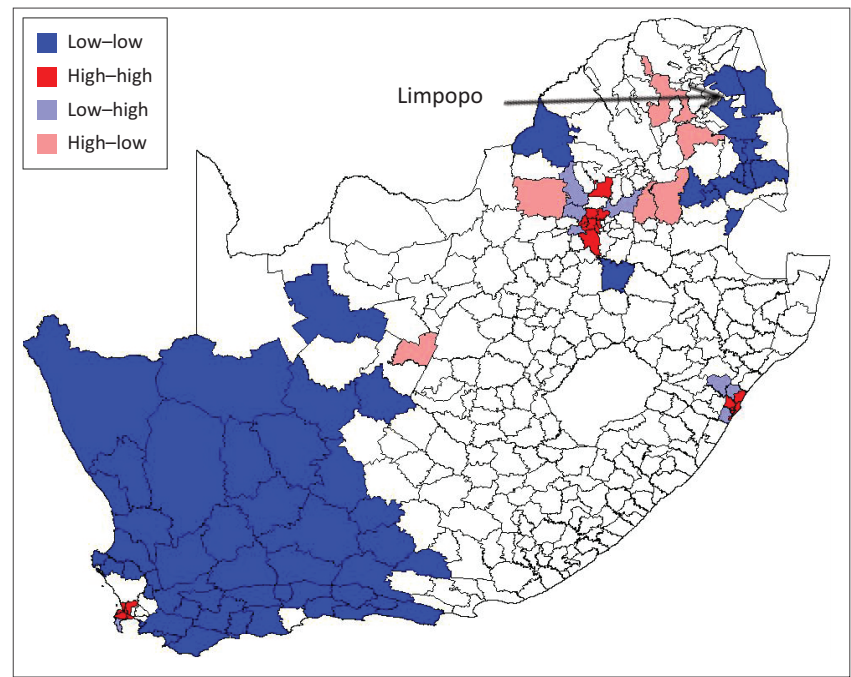

FIGURE 5: Local indication of spatial association map of Vulnerability Intervention Index estimates.

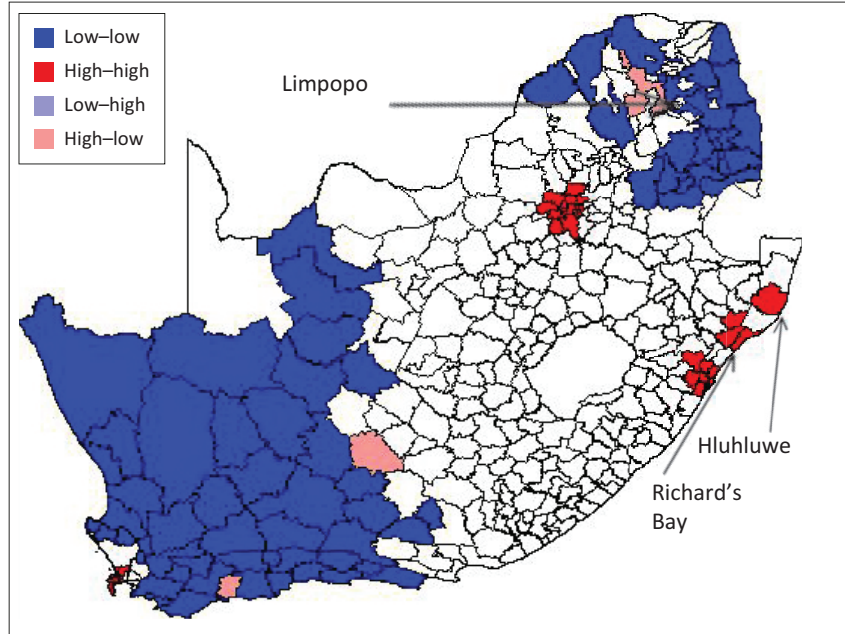

FIGURE 6: Local indication of spatial association map of Spatially Weighted Vulnerability Intervention Index estimates.

places when the VII and sVII estimates are compared, many of the ranks of the other districts detailed do change rank substantially.

Several observations can be made when interpreting Table 3 together with Figures 5 and 6. Firstly, the association of urbanisation and vulnerability alleviation, perhaps associated with agglomeration economies, around Johannesburg, Cape Town, Durban, Richard's Bay and Hluhluwe is much clearer from the visual examination of Figure 6, where the residuals are the result of an equation that explicitly considered spatial spillovers. Many economic geographers would expect this result.

Secondly, although Figures 5 and 6 highlight large areas of central South Africa in white, therefore suggesting that the areas are not performing substantially different than expected given their GDP per capita level, and the Northern and Western Capes have much worse vulnerability rates than we would expect given their GDP per capital levels, the area of greatest disparity between the VII and sVII estimates are in the province of Limpopo. The sVII perspective suggests that Limpopo is an area that deserves much more policy focus as spatial spillovers are resulting in much deeper vulnerability than one would otherwise expect. Policy directed towards individual magisterial districts in isolation within Limpopo will probably be relatively inefficient as the province requires a more holistic policy approach which explicitly accounts for spatial spillovers

Thirdly, the values of the VII shown in Table 3 do not have a large spread: the value for the 15th highest spatially ranked district (Bloemfontein) is equal to 1.88 , whereas the value for the bottom spatially ranked district (Pelgrimsrus) is equal to -1.34. This is in contrast to the top 14 spatially ranked districts, which vary between 6.47 (Johannesburg, 1st) and 2.05 (Cape Town, 14th). Further examination of this data is carried out using the multivariate Moran scatterplot, as show in Figure 7, which presents the sVII estimates on the horizontal axis and the sLVI on the vertical axis. Initial execution of this technique 


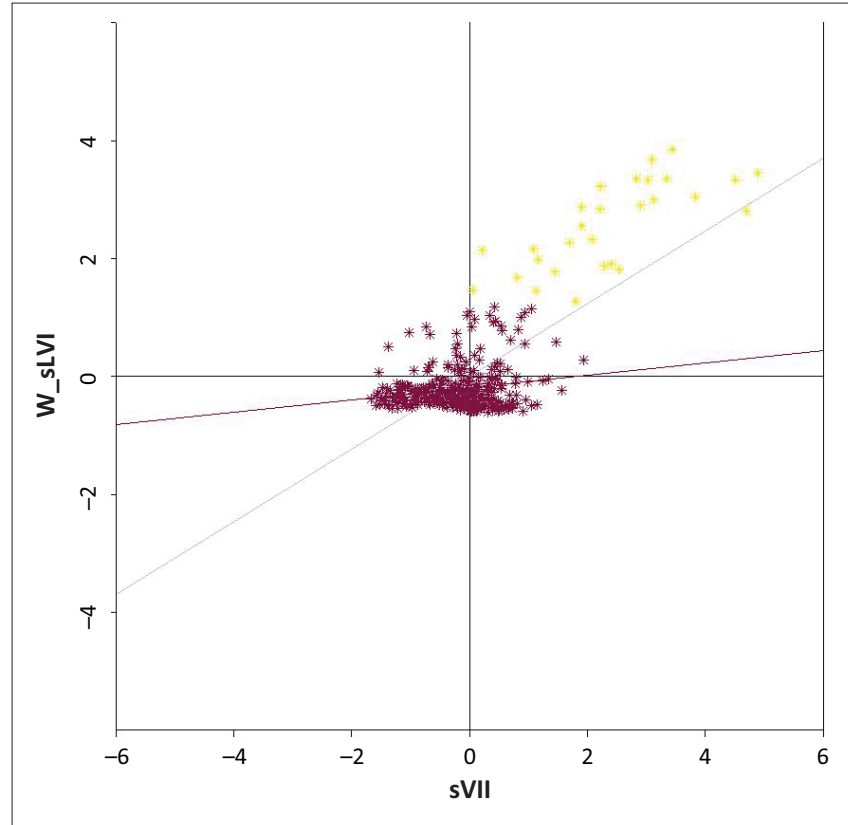

Note: Moran's I = 0.6163; I = 0.1038

FIGURE 7: Multivariate Moran scatterplot.

reveals a strong, statistically significant Moran's I value of 0.616 , but the exclusion of these top 14 ranked areas reveals a much shallower Moran's I value of 0.104. Although this latter value is still statistically significant, it becomes clear that a substantial part of the spatial correlation between SVII and sLVI is because of a large conurbation effect.

The large conurbation effect reflects the fact that those areas that are wealthier also have better vulnerability values. Such attributes could be because of the benefits of agglomeration, typically associated with urbanisation and location economies, but may also be because of national policies that are geared towards improving the lives of urban dwellers rather than their rural counterparts. This is in line with Friedmann (1963), Alonso (1968) and Yang (1999) who found that regional policies are biased in that they are likely to reflect the development of the urban areas as they are seem to have the most potential for development but ultimately cause greater spatial inequality. Little (2009) found that government policy needs to change in order to rectify the geographical imbalances in both recorded and hidden unemployment in urban and rural areas. Etherington and Jones (2009) argued that the policies implemented for city-regions emphasise and have the potential to increase, rather than resolve, uneven development and socio-spatial inequalities.

\section{Spatial lag and spatial error models}

There is an alternative method of generating estimates of sVII using spatial econometrics. The first stage is to estimate a standard ordinary least squares (OLS) estimate of $L V I_{i}=\alpha+\beta Y_{i}+\mu_{i}(i=1, \ldots, 354)$ and to incorporate a spatial weights matrix to permit the diagnosis of spatial dependence. This can be carried out using the GeoDa freeware, as employed above to generate spatial weights. Application of the OLS procedure yields results presented in Table 4 .
TABLE 4: Spatial econometrics $(N=354)$.

\begin{tabular}{llll}
\hline Econometrics & OLS & Spatial error & Spatial lag \\
\hline GDP & $1.121^{*}(0.079)$ & $0.858^{*}(0.060)$ & $0.752^{*}(0.061)$ \\
Lambda & - & $0.794^{*}(0.037)$ & - \\
Spatial lag & - & - & $0.688^{*}(0.036)$ \\
Constant & $-1.582(0.079)$ & $-0.019(0.251)$ & $-0.013(0.054)$ \\
Moran's I (error) & $0.577^{*}$ & - & - \\
Lagrange multiplier (lag) & $293.406^{*}$ & - & - \\
Robust LM (lag) & $19.486^{*}$ & - & - \\
Lagrange multiplier (error) & $311.063^{*}$ & - & - \\
Robust LM (error) & 37.143 & - & - \\
Likelihood ratio test for & - & $240.626 *$ & $227.674 *$ \\
spatial dependence & & & \\
Breusch-Pagan & 2.090 & 0.011 & 1.060 \\
Log-likelihood & -642.191 & -521.878 & -528.354 \\
$R^{2}$ & 0.362 & 0.726 & 0.701 \\
\hline
\end{tabular}

GDP, gross domestic product; LM, Lagrange multiplier; OLS, ordinary least squares. *, Statistically significant.

Several values presented in Table 4 are worth emphasising. Firstly, the GDP value is greater than unity, suggesting that a one unity increase in GDP will result in a larger than one-unit increase in the LVI. This would lead to the conclusion that, on average, GDP has a stronger than proportional effect on the LVI thereby emphasising that GDP is vital to the alleviation of vulnerability. That GDP is important for the LVI is not surprising, but this very strongly emphasises the importance of policies designed to stimulate the economy of South Africa so that they can 'grow out of vulnerability'. Although this result is based on the multidimensional PCA estimation of the LVI, the result does not support a multidimensional policy alleviation perspective.

Secondly, the Moran's I statistic indicates that there is strong spatial autocorrelation in the errors. This implies that an area's LVI value is very strongly and positively associated with its contiguous areas' LVI values and that policies to reduce vulnerability should not target areas in isolation; policy-makers should examine the cause and consequences of spatial spillovers that contribute to an area's vulnerability.

Thirdly, the Lagrange multiplier and robust Lagrange multiplier statistics indicate that the preferred spatial econometric model is the spatial error model, although this is by no means definite. If there were strong theoretical reasoning to believe that the errors of an OLS regression would be spatially autocorrelated, then the appropriate technique is to estimate a spatial error model, which in our case is specified as follows:

$L V I_{i}=\alpha+\beta Y_{i}+\mu_{i}$

[Eqn 3]

where

$\mu_{i}=\rho W u_{i}+\varepsilon_{i}$

[Eqn 4]

in which $\rho$ represents the spatial error parameter to be estimated, $W$ represents our spatial queen-weights matrix such that $W u$ captures the spatial lags of the model's disturbance term, $u$, and $\varepsilon$ represents the independently distributed error term. Under this specification, spatial 
autocorrelation of the LVI is the result of exogenous influences captured in the error term and not directly from the GDP explanatory variable. Selection of the spatial error model tends to be because of the list of explanatory variables excluding a variable that may have otherwise captured the spatial autocorrelation of the LVI.

The results of the spatial error model are also presented Table 4. The spatial error results are noticeably different from the OLS results in the following ways. Firstly, Lambda is positive and strongly statistically significant. This indicates that the spatial component in the error term is capturing some positive spatial autocorrelation, again suggesting spatial spillovers between contiguous areas are important in influencing an area's economic vulnerability.

Secondly, inclusion of Lambda strongly affects the coefficient of GDP. Interpretations of this effect can be numerous. One option is that the OLS coefficient for GDP included both the effects of GDP on LVI and the spatial spillover component and that entering the spatial spillover effect separately reveals the effect of GDP on LVI once we hold the spatial spillover effect constant. Contrary to the OLS results, the magnitude of the GDP coefficient is now less than unity, suggesting that a one-unit increase in GDP will result in a smaller than one-unit increase in the LVI. Now this leads to the conclusion that, on average, GDP has a smaller than proportional effect on the LVI, thereby emphasising that although GDP is important in the alleviation of vulnerability, the economy needs to grow substantially more to achieve a measured reduction in vulnerability than was suggested in the OLS results.

Thirdly, although the proportion of the variation of the LVI that is now explained by the model has increased substantially from 0.36 to over 0.7 , there is still evidence of spatial dependence as indicated by the likelihood ratio test.
As the Lagrange multiplier tests were not conclusive about whether the model should be estimated with either a spatial error or a spatial lag, it is worth complementing the spatial error results with the spatial lag results. The spatial lag model captures spatial autocorrelation as an explanatory variable, which in our case will take the following form:

$L V I_{i}=\alpha+\lambda W L V I_{i}+\beta Y_{i}+\mu_{i}$

[Eqn 5]

In our formulation, WLVI is the queen-contiguous spatially weighted average of the dependent variable for area $i$ and $\lambda$ is the spatial lag parameter to be estimated.

Although the results of the spatial error and spatial lag models originate from different theoretical concerns for the origins of spatial spillovers, our results for the spatial lag and spatial error models effectively corroborate each other: the magnitude of the impact of GDP on the LVI is positive and around 0.8 , and therefore, GDP does not have a more than proportional effect on LVI. Therefore, there may be important roles in vulnerability alleviation associated with factors other than stimulating GDP.

The residuals of the three models whose results are presented in Table 4 were retained, as before, to identify the top and bottom ranked areas and are presented in Tables 5 and 6 . A number of important issues that corroborate our previous results can be made.

Firstly, the most consistent set of results are identifiable for the top seven regions. All three model estimates suggest that Cape Town is the least vulnerable. All three models suggest that the next six areas are consistently in the top 15 area for low amounts of vulnerability. These results hold when the spatial and aspatial perspectives are accounted for, but this time using the spatial error and spatial lag models. Also of note is how the magnitudes of the residual values are relatively stable, large and positive for these seven areas.

TABLE 5: Top ranks by model.

\begin{tabular}{|c|c|c|c|c|c|c|}
\hline Area name & OLS residual & Top OLS rank & Spatial lag residual & Top lag rank & Spatial error residual & Top error rank \\
\hline Cape Town & 7.667395 & 1 & 5.718656 & 1 & 5.616770 & 1 \\
\hline Soweto & 6.181829 & 2 & 4.046200 & 3 & 3.755192 & 3 \\
\hline Mitchells Plain & 5.071464 & 3 & 2.537897 & 9 & 2.493274 & 8 \\
\hline Johannesburg & 4.616083 & 4 & 2.448210 & 10 & 2.303956 & 9 \\
\hline Vanderbijlpark & 4.432274 & 5 & 3.462426 & 5 & 3.148792 & 5 \\
\hline Umlazi & 4.404667 & 6 & 2.013840 & 14 & 2.051522 & 12 \\
\hline Germiston & 3.560221 & 8 & 0.253805 & 113 & 0.695987 & 69 \\
\hline Wynberg & 3.543811 & 9 & 0.193176 & 123 & -0.113391 & 172 \\
\hline Goodwood & 3.327346 & 10 & 0.040754 & 140 & -0.325927 & 207 \\
\hline Pretoria & 3.326061 & 11 & 2.053859 & 12 & 2.230983 & 10 \\
\hline Benoni & 3.278169 & 12 & 1.480079 & 27 & 1.739241 & 17 \\
\hline Alberton & 3.231379 & 13 & 1.259960 & 34 & 1.343254 & 29 \\
\hline Durban & 3.222810 & 14 & 1.202821 & 38 & 1.076926 & 38 \\
\hline Randburg & 3.106678 & 16 & 1.005883 & 50 & 1.141873 & 35 \\
\hline Kuils River & 2.980157 & 17 & 0.701022 & 77 & 0.575824 & 86 \\
\hline Umbumbulu & 2.896122 & 18 & 1.293591 & 32 & 1.309618 & 31 \\
\hline Welkom & 2.786820 & 19 & 3.504635 & 4 & 1.959624 & 13 \\
\hline Kempton Park & 2.725254 & 20 & 0.263465 & 111 & 0.501135 & 89 \\
\hline
\end{tabular}


TABLE 6: Bottom ranks by model.

\begin{tabular}{|c|c|c|c|c|c|c|}
\hline Area name & OLS residual & Bottom OLS rank & Spatial lag residual & Bottom lag rank & Spatial error residual & Bottom error rank \\
\hline Williston & -1.615568 & 335 & -0.491418 & 233 & -0.393317 & 219 \\
\hline Bizana & -1.685157 & 336 & -0.900947 & 304 & -0.884931 & 303 \\
\hline Willowvale & -1.708555 & 337 & -0.476700 & 228 & -0.394206 & 220 \\
\hline Peddie & -1.711375 & 338 & -2.025694 & 354 & -1.849968 & 353 \\
\hline Port St Johns & -1.714403 & 339 & -0.628967 & 258 & -0.668032 & 268 \\
\hline Ngqueleni & -1.729913 & 340 & -0.916558 & 305 & -0.882046 & 302 \\
\hline Kudumane & -1.923607 & 342 & -0.824197 & 295 & -0.778068 & 284 \\
\hline Excelsior & -1.980283 & 343 & -1.306848 & 335 & -1.343327 & 341 \\
\hline Kenhardt & -1.989634 & 344 & -1.256703 & 331 & -1.072313 & 326 \\
\hline Huhudi & -2.007710 & 345 & -1.382568 & 338 & -1.206012 & 333 \\
\hline Volksrust & -2.016398 & 346 & -0.099554 & 165 & -0.868144 & 297 \\
\hline Mpofu & -2.017103 & 347 & -1.761701 & 353 & -1.745970 & 352 \\
\hline Laingsburg & -2.025299 & 348 & -1.705216 & 352 & -1.476800 & 344 \\
\hline Carnarvon & -2.104649 & 350 & -0.965756 & 312 & -0.832664 & 293 \\
\hline Postmasburg & -2.120007 & 351 & -0.504739 & 237 & -0.487202 & 239 \\
\hline Idutywa & -2.301529 & 352 & -1.253387 & 330 & -1.231718 & 336 \\
\hline Herbert & -2.401343 & 353 & -1.673748 & 350 & -1.526984 & 346 \\
\hline Elliotdale & -2.521465 & 354 & -1.246596 & 328 & -1.132202 & 330 \\
\hline
\end{tabular}

Secondly, there is substantial rank switching at the bottom end between the aspatial and spatial models. For instance, out of the bottom 20 in the OLS, only six remain in the bottom 20 using either of the spatial models. Also noticeable is that there is substantial rank switching at the top end between the aspatial and spatial models. For instance, ignoring the top seven, out of the next 13 in the OLS results, only two remain in the top 20 using either of the spatial models. Taken together, these results indicate that the method of analysis is important when identifying the relative vulnerability position of areas.

Thirdly, when the magnitude of the difference in the residual values are observed, it appears that the gaps in vulnerability are much smaller between areas that do not make up the top seven, which are areas that are very urban. This highlights the importance of the urban-rural divide in vulnerability terms and that the beneficial effects of urbanisation on vulnerability does not reach far into rural areas to alleviate vulnerability.

\section{Caveats, conclusions and avenues for future research}

This article aimed to provide a purely methodological contribution to the existing literature regarding measurement and analysis of regional vulnerability through extending the methodology introduced by Naudé et al. (2009b). Through augmenting and expanding on their index methods, emphasis was placed on the need for recognition of the spillovers in economic vulnerability that may be present within a country at a sub-national level. Vulnerability indicators therefore must take into account spatial spillovers if they are economically significant. Application of the extensions to South African Magisterial District data illustrates the presence and importance of spatial spillovers in shaping local vulnerability. It is argued that account of spatial spillovers is an important issue if full and accurate vulnerability indices are to be identified.

Our results illustrate a clear urban-rural vulnerability divide and the need for appropriate policy. If policies are going to be focused on improving vulnerability, then policy-makers must decide whether to invest in urban areas, where economic growth and development are typically at their greatest and where a vast majority of a country's population resides, or across whole swathes of countryside, and achieves a more holistic reduction in vulnerability. Governments should be aware that if they choose the wrong policy, then they may accentuate the problem and it would appear that their policies have failed.

Although this article does make a methodological contribution and will influence future regional vulnerability studies, it is not without its caveats. The lack of addressing institutional quality, which is highly uneven across magisterial districts and is evident from the rise in violent protests against lack of service delivery, is unfortunately a domain this article cannot capture with the present available regional data set.

Avenues for future research should be aimed at reproducing this article with the most recent data available in order to determine possible changes in vulnerability patterns which could be because of possible changes in South Africa's economic landscape. With the fourth wave of National Income Dynamics Study (NIDS) data available, potential exists to include variables regarding service delivery, infrastructure shortages and individual opportunities and rights.

\section{Acknowledgements}

The author would like to thank Professor Don Webber from the University of West England, Bristol, for helpful comments on earlier drafts. All errors remain the author's responsibility. 


\section{Competing interests}

The author declares that she has no financial or personal relationship(s) that may have inappropriately influenced her in writing this article.

\section{References}

Alderman, H., Babita, M., Lanjouw, J., Lanjouw, P., Makhatha, N., Mohamed, A. et al., 2000 , 'Combining census and poverty data to construct a poverty map of South Africa', in R. Hirschowitz (ed.), Measuring poverty in South Africa, pp. 5-52, Statistics South Africa, Pretoria, viewed 16 June 2009, from www.dti.gov.za/ econdb/poverty.pdf

Alonso, W., 1968, 'Urban and regional imbalances in economic development', Economic Development and Cultural Change 17(1), 1-14. https://doi.org/ $10.1086 / 450324$

Anderson, E., 2007, Identifying chronically deprived countries: Results from cluster analysis, CPRC Working Paper no. 70, ODI, London.

Anselin, L., 1995, 'Local indicators of spatial association - LISA', Geographical Analysis 27, 93-115. https://doi.org/10.1111/j.1538-4632.1995.tb00338.x

Anselin, L., 1996, 'The Moran scatterplot as an ESDA tool to assess local instability in geographical association', in M. Fisher, H.J. Scholten \& D. Unwin (eds.), Geographical analytical perspectives on GIS, pp. 111-125, Taylor and Francis, London.

Atkins, J., Mazzi, S. \& Easter, C., 2000, A commonwealth vulnerability index for developing countries: The position of small states, Economic Paper No. 40, Commonwealth Secretariat, London.

Baliamoune-Lutz, M. \& McGillivray, M., 2008, State fragility, WIDER Research Pape 2008/44, UNU-WIDER, Helsinki.

Bird, K., McKay, A. \& Shinyelawa, I., 2007, 'Isolation and poverty in Uganda: Applying an index of isolation', paper presented at the International Workshop on 'Understanding and Addressing Spatial Poverty Traps', Stellenbosch, South Africa, 29 March.

Bird, K. \& Prowse, M., 2008, Vulnerability, poverty and coping in Zimbabwe, WIDER Research Paper 2008/41, UNU-WIDER, Helsinki.

Birkmann, J., 2007, 'Assessing vulnerability before, during and after a disaster of natural origin: A case study of the tsunami in Sri Lanka and Indonesia', paper presented at the UNU-WIDER Conference on Fragile States-Fragile Groups, Helsinki, 15-16 June.

Briguglio, L., 1995, 'Small island developing states and their economic vulnerabilities', World Development 23(9), 1615-1632. https://doi.org/10.1016/0305-750X(95) 00065-K

Briguglio, L., 1997, Alternative economic vulnerability indices for developing countries, Report prepared for the United Nations Department of Economic and Social Affairs, UN, New York.

Briguglio, L. \& Galea, W., 2003, Updating the economic vulnerability index, occasional papers on Islands and Small States no. 2003-4, Islands and Small States Institute, University of Malta, Malta.

Calvo, C., 2008, 'Vulnerability to multidimensional poverty: Peru, 1998-2002', World Development 36(6), 1011-1020. https://doi.org/10.1016/j.worlddev.2007.10.001

Chaudhuri, S., Jyotsna, J. \& Suryahadi, A., 2002, Assessing household vulnerability to poverty from cross-sectional data: A methodology and estimates from Indonesia, Discussion Paper Series 0102-52, Department of Economics, Columbia University, Columbia.

Chauvet, L. \& Collier, P., 2005, Developmental effectiveness in fragile states: Spillover and turnarounds, Centre for the Study of African Economics, Oxford University, Oxford.

Chauvet, L., Collier, P. \& Hoeffler, A., 2007, Paradise lost: The costs of state failure in the Pacific, WIDER Research Paper 2007/16, UNU-WIDER, Helsinki.

Country Indicators for Foreign Policy (CIFP), 2006, Failed and fragile states 2006: A briefing note for the Canadian government, CIDA, Ottawa.

Demombynes, G. \& Özler, B., 2005, 'Crime and local inequality in South Africa', Journa of Development Economics 76(2), 265-292. https://doi.org/10.1016/j.jdeveco. 2003.12.015

Easter, C., 1998, 'Small states and development: A composite index of vulnerability', in Small states: Economic review and basic statistics, Annual Series 4, pp. 1-236, Commonwealth Secretariat, London.

Etherington, D. \& Jones, M., 2009, 'City-regions: New geographies of uneven development and inequality', Regional Studies 43(2), 247-265. https://doi.org/ $10.1080 / 00343400801968353$

Florax, R.J.G.M. \& van der Vlist, A.J., 2003, 'Spatial econometric data analysis: Moving beyond traditional models', International Regional Science Review 26(3), 223-243. https://doi.org/10.1177/0160017603254937

Friedmann, J., 1963, 'Regional economic policy for developing areas', Papers in Regional Science 11(1), 41-61. https://doi.org/10.1007/BF01943194

Gaiha, R. \& Imai, K., 2008, Measuring vulnerability and poverty: Estimates for rura India, WIDER Research Paper 2008/40, UNU-WIDER, Helsinki.

Glaeser, E.L., Laibson, D.I., Scheinkman, J.A. \& Soutter, C.L., 2000, 'Measuring trust', Quarterly Journal of Economics 155, 811-846. https://doi.org/10.1162/003355 300554926
Glewwe, P. \& Hall, G., 1998, 'Are some groups more vulnerable to macroeconomic shocks than others? Hypothesis tests based on panel data from Peru', Journal of Development Economics 56(1), 181-206. https://doi.org/10.1016/s0304Development Econc

Greyling, T. \& Rossouw, S., 2016, 'Non-economic quality of life and population density in South Africa', Social Indicators Research, 1-25. https://doi.org/10.1007/ s11205-016-1468-1

Guillaumont, P., 2004, 'On the economic vulnerability of low income countries', in L. Briguglio \& E.J. Kisanga (eds.), Economic vulnerability and resilience of small states, pp. 54-71, Islands and Small States Institute of the University of Malta, Malta.

Guillaumont, P., 2009, 'An economic vulnerability index', Oxford Development Studies 37(3), 193-228. https://doi.org/10.1080/13600810903089901

Hulme, D., Moore, K. \& Shepherd, A., 2001, Chronic poverty: Meanings and analytical frameworks, CPRC Working Paper no. 2, Institute of Development Policy and Management, Manchester.

IHS Regional Economic Explore, 2014, IHS's Regional Economic Focus (REF) (Data set), n.d., from http://www.ihsglobalinsight.co.za/

Irwin, E. \& Bockstael, N., 2004, 'Endogenous spatial externalities: Empirical evidence and implications for the evolution of exurban residential land use patterns', in L. Anselin, R.J.G.M. Florax \& S.J. Rey (eds.), Advances in spatia econometrics: Methodology, tools and applications, pp. 359-380, Springer, Berlin.

Ivaschenko, O. \& Mete, C., 2008, Asset-based poverty in rural Tajikistan, WIDER Research Paper 2008/26, UNU-WIDER, Helsinki.

Kanbur, R. \& Venable, A.J., 2005, Rising spatial disparities and development, Policy Brief 2005/3, UNU-WIDER, Helsinki.

Klasen, S., 2000, 'Measuring poverty and deprivation in South Africa', Review of Income and Wealth 46(1), 33-58. https://doi.org/10.1111/j.1475-4991.2000. tb00390.x

Kühl, J.J., 2003, Disaggregating household vulnerability - Analyzing fluctuations in consumption using a simulation approach, Manuscript, Institute of Economics, University of Copenhagen, Denmark.

Liou, F.M. \& Ding, C.G., 2004, 'Positioning the non-least developed developing countries based on vulnerability related indicators', Journal of Internationa Development 16, 751-767. https://doi.org/10.1002/jid.1095

Little, A., 2009, 'Spatial pattern of economic activity and inactivity in Britain: People or place effects?', Regional Studies 43(7), 877-897. https://doi.org/10.1080/ 00343400801968395

Lubotsky, D. \& Wittenberg, M., 2006, 'Interpretation of regressions with multiple proxies', The Review of Economics and Statistics 88(3), 549-562. https://doi. org/10.1162/rest.88.3.549

Mansuri, G. \& Healy, A., 2001, Vulnerability prediction in rural Pakistan, World Bank, Washington, DC

Marchante, A.J. \& Ortega, B., 2006, 'Quality of life and convergence across Spanish regions, 1980-2001', Regional Studies 40(5), 471-483. https://doi. org/10.1080/00343400600757460

Mattes, R., Bratton, M. \& Davids, Y.D., 2003, Poverty, survival and democracy in Southern Africa, Afrobarometer Working Paper 23, IDASA, Cape Town, viewed 21 October 2010, from www.afrobarometer.org/papers/Afropaper No23.pdf

Matthee, M. \& Naudé, W.A., 2007, Export diversity and regional growth: Empirical evidence from South Africa, WIDER Research Paper 2007/11, UNU-WIDER, evidence
Helsinki.

Mauro, P., 1995, 'Corruption and growth', Quarterly Journal of Economics 110(3), 681-712. https://doi.org/10.2307/2946696

McDonald, S. \& Roberts, J., 2006, 'AIDS and economic growth: A human capital approach', Journal of Development Economics 80(1), 228-250. https://doi.org/ 10.1016/j.jdeveco.2005.01.004

McGillivray, M., Naudé, W.A. \& Santos-Paulino, A.U., 2008, 'Achieving growth in the Pacific Islands: Introduction', Pacific Economic Bulletin 23(3), 97-101.

Municipal Demarcation Board of South Africa (MDB), 2016, Municipal boundaries, viewed 16 June 2016, from http://www.demarcation.org.za/site/

National Planning Commission (NPC), 2013, Our Future - Make It Work. Nationa Development Plan - 2030, viewed 27 July 2016, from http://www.gov.za/issues/ national-development-plan-2030

Naudé, W.A., Gries, T., Wood, E. \& Meintjes, A., 2008, 'Regional determinants of entrepreneurial start-ups in a developing country', Entrepreneurship and Regional Development 20(2), 111-124. https://doi.org/10.1080/08985620701631498

Naudé, W.A., Krugell, W.F. \& Rossouw, S., 2009a, 'The non-monetary quality of city life in South Africa', Habitat International 33(4), 319-327. https://doi.org/10.1016/j. habitatint.2008.08.004

Naudé, W.A., McGillivray, M. \& Rossouw, S., 2009b, 'Measuring the vulnerability of sub-national regions in South Africa', Oxford Development Studies 37(3), 249-276. https://doi.org/10.1080/13600810903085800

Noble, M., Babita, M., Barnes, H., Dibben, C., Magasela, W., Noble, S. et al., 2006, The provincial indices of multiple deprivation for South Africa 2001: Technical report, HSRC and Statistics SA, Pretoria, viewed 08 March 2010, from www.statssa.gov. za/census01/HTML/PMID/PIMDTechnicalReport2006.pdf

OECD, 2015, National accounts at a glance 2015, OECD Publishing, Paris, viewed 27 July 2016, from https://doi.org/10.1787/na_glance-2015-en

Rodgers, E.M., 1962, Diffusion of innovation, The Free Press, New York. 
Rossouw, S. \& Naudé, W.A., 2008, 'The non-economic quality of life on a sub-national level in South Africa', Social Indicators Research 86(3), 433-452. https://doi. org/10.1007/s11205-007-9178-3

Tobler, W., 1970, 'A computer movie simulating urban growth in the Detroit region', Economic Geography 46(2), 234-240. https://doi.org/10.2307/143141

Tondl, G. \& Vuksic, G., 2003, What makes regions in Eastern Europe catching up? The role of foreign investment, human resources and geography, Centre for European Integration Studies Working Paper B12/2003, University of Bonn, Bonn.

Turvey, R., 2007, 'Vulnerability assessment of developing countries: The case of smal island developing states', Development Policy Review 25(2), 243-264. https://doi. org/10.1111/j.1467-7679.2007.00368.x
USAID, 2006, Fragile state indicators. A supplement to the country analytical template, Washington, DC, viewed 28 July 2016, from http://pdf.usaid.gov/pdf_docs/ Pnadg262.pdf

Voss, P.R., Long, D.D., Hammer, R.B. \& Friedman, S., 2006, 'Country child poverty rates in the US: A spatial regression approach', Population Research Policy Review 25, 369-391. https://doi.org/10.1007/s11113-006-9007-4

Ward, N. \& Brown, D.L., 2009, 'Placing the rural in regional development', Regional Studies 43(10), 1237-1244. https://doi.org/10.1080/00343400903234696

Yang, D.T., 1999, 'Urban-biased polices and rising income inequality in China', The American Economic Review 89(2), 306-310. https://doi.org/10.1257/aer. 89.2.306 